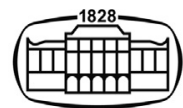

AKADÉMIAI KIADÓ

\title{
Ethnopharmacologic search for psychoactive drugs
}

\section{Michael James Winkelman}

\section{Journal of Psychedelic Studies}

4 (2020) 2, 73-76

DOI:

$10.1556 / 2054.2020 .00141$

(c) 2020 The Author(s)

\section{BOOK REVIEW}

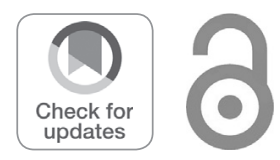

E-mail: michaeljwinkelman@gmail. com
School of Human Evolution and Social Change, Arizona State University (retired), USA

Prance, G., McKenna, D., De Loenen, B., and D, Wade (Eds.) (2018). Ethnopharmacologic search for psychoactive drugs (Vol. 1 \& 2): 50 years of research. Santa Fe, NM: Synergetic Press. Vol. 1: 468 pages plus introductory material; Vol. 2: 330 pages plus introductory material; USD125/19.99 hard copy/e-book. ISBN 10: 0907791689/ISBN 13: 9780907791683

Received: April 26, 2020 • Accepted: June 6, 2020

Published online: July 27, 2020

These two volumes bring together two very different eras of psychedelic studies, its early florescence in the 1960s and a current wave reflecting cumulative developments fifty years later. Both are based on conferences sharing the same title given to the book, an open exploration of the potential for modern science and medicine to engage with the pharmacological abundance provided by nature and embodied in the remnants of shamanic entheogenic traditions.

The first volume covers an international conference including researchers from diverse fields - psychiatry, medicine, botany, pharmacology, chemistry and anthropology - that came together in San Francisco in 1967 for three days under what might have been seen as auspicious circumstances - a conference sponsored by agencies of the US government, the National Institute of Mental Health and US Public Health Service. The second volume is the compilation of 21 papers presented 50 years later in 2017 when an even more diverse group of scholars came together to share some of the new findings that emerged since the first conference, reflecting the psychedelics renaissance that emerged in the 21st century during a stifling decades long War on Drugs funded by the same government that sponsored the first conference 50 years ago. As the second volume shows, in spite of such draconian repression, the field of ethnopharmacological psychedelic studies has progressed to the point that we are now able to discuss the numerous discoveries of the therapeutic potential of these diverse substances in spite of their continued stigmatization.

The first conference included a who's who of 20th century psychedelic research with such famous stalwarts as Richard Evans Schultes, Gordon Wasson, Claudio Naranjo, Alexander Shulgin, and Daniel Freedman, but the majority of the participants are probably but historical footnotes to their 21 st century intellectual descendants. Their presentations at this conference, however, are immortalized in this publication, first released in 1967 as Public Health Service Publication No. 1645 by the US Government Printing Office under the editorship of Daniel Efron, Bo Holmstedt and Nathan Kline. While the conference was dominated by US researchers, the international scope of the participants was reflected in researchers from Russia, Argentina, Mexico, Switzerland, Germany and Sweden.

Efron's preface alludes to issues still important and unresolved in the study of psychedelics such as the origins of humans' psychotropic plant use and the identity of the psychoactive plants referred to in the Bible. Efron's naivety is evident however, where he wonders if this Biblical drug use "brought happiness and comfort, or new problems, aggravations, and unhappiness" (p. ix). Apparently Efron's memory of Sunday school teachings had faded as Genesis clearly tells us that the gods were definitely displeased with humans taking the fruit from the Tree of Knowledge of good and evil, and fearing that humans would also use this knowledge to partake of the Tree of Immortality, the gods banished Adam and Eve from an idyllic Eden and sent them to toil and suffer in the outside world. Seems like this early engagement with psychotropics provoked the first war on drugs!

The focus of the conference was however, not on such weighty theological issues but on the importance of knowledge about plant compounds, the ethnopharmacological search for 
psychoactive drugs as the conference and book title pronounced. The 1967 conference's coverage of topics may seem a bit strange from a current perspective, as many of the topics are at best peripheral to contemporary psychedelic studies. Following an introductory session providing "An Overview of Ethnopharmacology" the conference turned to a virtually unimportant topic in today's world of psychedelic research in a session on "Piper Methysticum (Kava)". This long-cultivated plant of Polynesia, Oceania, Micronesia and New Guinea is scarcely a topic in contemporary drug research, but half a century ago it already commanded serious scientific attention. This is evidenced in the introduction and 8 presentations addressing kava's cultural uses, chemistry, pharmacology, and behavioral dynamics. Contemporary research attests to kava's multiple modes of action with interactions with a variety of neuroreceptors, including GABA, serotonin, opioid and dopamine.

The second session on "Myristica Fragens (Nutmeg)" similarly represents issues long faded from the mainstream concerns with psychedelic drugs (but it did give me a flashback to several episodes in high school when I experimented with snorting the spice after I was introduced to it by the DARE Program!). The presenters and discussions were rounded out by no lesser figures than Alexander Shulgin, Claudio Naranjo and Andrew Weil.

The third session on "South American Snuffs" continued a trend of focusing on topics of little contemporary concern, but which in this case nonetheless may be of considerable current importance. Bo Holmstedt, Henry Wassen, Richard Schultes, Siri von Reis Altschul, Georg Seitz and Jan-Erik Lindgren provided presentations on diverse topics ranging from: an overview of anthropological studies of South American snuffs; assessments of the botanical origins, chemical constituents and pharmacological actions of the snuffs; descriptions of the use of vilca and epnea; and diverse discussions of these tryptamine derivatives. While these powerful psychoactive substances have received scant attention in recent years, they remain a significant issue not only among indigenous cultures of South America, but also among some urban populations of South America.

A session on "Ayahuasca, Caapi and Yage" reflects interests of considerable contemporary popularity in psychedelic studies. This session reflects the impoverished beginnings of this field of study, with just three papers on the psychotropic properties, chemical compounds and preparation processes reflecting an area of interest that was just beginning to pique the academic community.

The final session on "Amanita Muscaria (Fly Agaric)" reflects another area that was of considerable significance 50 years ago, but which has since faded from the focus of contemporary psychedelic studies. Papers on the pharmacology and active compounds are mostly of historical interest, while others on ethnopharmacological aspects of Amanita may still have relevance to those interested in the cultural context of this enigmatic fungi which has remained at the margins of current psychedelic studies.

The second volume covers a second conference convened at Tyringham Hall, Buckinghamshire England in June of
2017. It followed the spirit of the first conference in inviting specialists from around the world and from diverse academic fields, not only ethnopharmacology, but also anthropology, botany, chemistry, and pharmacology to explore the state and potential of the study of psychoactive plants. While the 50 year interlude certainly also produced an enormous ethnopharmacological literature on psychoactive plant compounds, including examinations of those with psychedelic properties, the War on Drugs beginning with the Nixon administration in the 1970s certainly put a global halt to much of the scientific research on these substances. Nonetheless by the beginning of the 21st century, a psychedelic renaissance had begun on many fronts.

The second volume opens with an article from an old report by Stephen Szára "A Scientist Looks at the Hippies," who in his capacity as NIMH employee carried out a rapid ethnographic assessment of several major urban foci of the psychedelic movement in 1967. Apart from its historical value, the article reveals a complex social scene that describes the cultural context of this counter-cultural drug consumption. It also contains what most would consider gross distortions ("drug usage leads very often to medical and psychiatric emergencies”) and was likely of eventual interest to the US Drug Enforcement Agency and other law enforcement agencies.

The only substantial continuity from the 1967 conference in major topics was ayahuasca, appropriately the first session of the conference. The session was dominated by anthropologists (Luis Eduardo Luna, Constantino Manuel Torres, Evgenia Fotiou and Glenn H. Shepard) who provided ethnographic and historical perspectives on what is arguably the most important survival of ancient cultural traditions of psychedelic plants use that persists today. Luna shows how the phenomenology of ayahuasca experience provide substantial epistemological challenges to scientific notions of personal identity, the dimensions of consciousness and the nature of reality. Luna addresses the concept of plant intelligences and relates the animistic worldview of ayahuasca to what science tells us about the cognitive and emotional effects.

Torres reviews documents from early historical periods that indicate a relative recency of ayahuasca, and he relates this beverage to other psychoactive beverage traditions of South American prehistory. The lack of archaeological evidence for ayahuasca (as opposed to many other psychoactives) and relatively late accounts of ayahuasca in the early historical period suggest that ayahuasca emerged in the 16th century from interactions among these earlier traditions.

Foutia's paper examines vegetalist traditions of the Peruvian Amazon, providing an in-depth consideration of the concept of dieta. This vegetalista tradition extends the basic ayahuasca diet (no beef, pork, salt, sugar, oils, spices, alcohol) and prohibitions of sex for 4 days before and 8 after. The dieta adds one or more plants for their spiritual or energetic qualities rather than strictly pharmacological or psychedelic effects. Such plants provide strength, protection, purging, cleansing, healing abilities, removal of dark energies, tranquility, and other powers against malevolent 
spirits that permit shamanic healing. This dieta may last days to months without ayahuasca in order to strengthens the person for healing or shamanic initiation and takes place in relative social isolation to provide the physical, psychological and spiritual cleaning necessary for healing and development.

Shepard presents ayahuasca and other shamanic substances as plant teachers and intelligences in an animistic perspective that cross-cuts traditional dualistic notions in seeing an integration of their mental, spiritual and physical properties. Shepard brings scientific data to bear on these perspectives in relating them to functions of messenger molecules that help to explain their interwoven biological, cultural, experiential and cosmological dimensions, revealing a biosemiotics of these shamanic practices.

Dale Millard expands on the understanding of the therapeutic applications of ayahuasca in a review of studies on diverse medicinal effects of harmine. This suggests its potential role in successfully treating not only psychological problems but a range of physical, chronic and infectious conditions through many potential preventive and restorative effects. Millard proposes that harmine's stimulation of neurogenesis and interactions (intercalation) with DNA provide significant areas for development of new medicines. The section ending essay by Mark Plotkin, Brian Hettler and Wade Davis brings a stimulating mini-biography of the life of Richard Evans Schultes.

The section "Africa, Australia and Southeast Asia" begins with Nigel Gericke's paper on the Australian succulent Kanna (Sceletium species), providing a historical overview of the use of still another old psychoactive that has become a worldwide phenomenon. Evidence shows that Kanna has shown promise for medical management of anxiety and depression, perhaps even addictions, and enhances cognitive function. A standardized extract of the plant has been commercialized and has been studied for use in clinical, veterinary and laboratory studies. The wide range of novel alkaloids found suggest a variety of medical applications. Christopher McCurdy's article provides perspectives on the use of Kratom (Mitragyna speciosa) as a treatment for opioid dependence, also now a worldwide phenomenon. Physician Kenneth Alper provides a significant update on another promising treatment for opioid dependence, ibogaine. His article provides a characterization of ibogaine's uniqueness as a "privileged scaffold" that provides a basic molecular framework prototypic of a class of compounds that allows for systematic substitutions to modulate therapeutic effects, providing possibilities for creating innovative pharmacotherapies. Jean-Francois Sobiecki provided comparative assessments of initiation into the use of psychoactive plants, contrasting South African and Amazonian traditions. In analyzing these initiations, he proposes they function as technologies for interrupting old behavioral patterns and enhancing awareness in ways that facilitate self-inquiry and growth. Snu Voogelbreinder discusses the use of dozens of Australian Acacia species, whose psychoactive alkaloids have a wide range of medicinal effects. David E. Nichols concludes this section with an article based on his keynote talk on the importance of structural elements of naturally sourced tryptamines, phenethylamines and ergoline alkaloids. These findings have led to discoveries of structureactivity relationships that explain their medicinal chemistry and permit the creation of new psychedelics molecules and therapies.

The section on "Mexico and Central America" begins with anthropologist Stacy Schaefer's paper on peyote's use and safe and beneficial effects on pregnancy, comparing it to ayahuasca use among pregnant church members. Schaefer's review of the clinical and laboratory studies illustrates how the chemical constituents enhance neuronal and physiological processes that reveal how medical science can help illuminate the biological rationale for indigenous practices. Keeper Trout's paper addresses conceptual confusion linking peyote, fermented drinks from Agave species, and Sophora secundiflora. The section concludes with a paper by Jerry Patchen, longtime lawyer for the Native American Church, which reflects on the history of peyote's legal struggles to find acceptance within the US justice system.

The final section of the book "Biosphere" addresses some of the ethnopharmacological methods and their value to scientific research. Jeanmaire Molina illustrates the value of cross-cultural research into traditional medicinal plant use, with the convergence of phylogenetic analysis with crosscultural similarity in patterns of cultural plant providing information for discovering significant phytochemicals and new drug sources. Converging cross-cultural patterns can lead to discovery of evolutionary conserved bioactivity and the likely medicinal properties of phylogenetically related plants. Ethnobotanical research provides methods for integrating the wisdom of centuries of plant screening for specific psychoactive effects, not only the entheogens that have captured the intention of psychedelic researchers, but many other areas as well.

Dennis McKenna's paper illustrates these kinds of applications in a summary of earlier research on several hundred Amazonian medicinal species. A potential for CNS action was detected in a high percentage of samples, and correlations were found between folk uses and relevant phytochemical constituents, identifying potential novel therapeutic compounds.

In the closing paper from their keynote presentation, Michael Heinrich and Ivan Casselman point out the multidisciplinary aspects of the transdisciplinary science of ethnopharmacology, cross-cutting botany, pharmacology, anthropology, and medicine. They illustrate some of the remaining challenges to a field that all to easily falls into the trap of expropriation of traditional knowledge.

The ethnopharmacologic search for psychoactive drugs is obviously a search for understanding of neurochemical mechanisms in the brain. But ethnopharmacology must also be true to its ethnographic = cultural roots, and those are entheogenic. The search for psychoactive drugs cannot be just an effort after biochemicals but must also be an ethnographic inquiry into the meaning and understandings of these forms of knowledge produced through the relationship of our brain with these phytochemicals. 
This impressive publication turns the tide again towards a recognition of the importance of the ethnographic component of ethnopharmacology, a focus on the traditional knowledge bases that provide the accumulated centuries, if not millennium, of plant knowledge derived from direct use and phenomenological observation. As a number of papers in this volume show, the ethnographic context of this use, including an understanding of the cosmologies and animistic belief systems that are produced by these ethnopharmacological traditions, must be part of this inquiry. The ethnographic traditions provide phenomenological experiences and a worldview that shows the incompleteness of the materialist paradigm. It may be true, as materialist perspectives allege, that all we know of reality is mediated through the neurochemical actions at our receptors. But what this opens up is Pandora's box of numerous neurochemically mediated realities. Those realities manifested under the influence of psychedelics manifest robust cross-cultural patterns and attest to a phenomenological reality. If this is not an indication of a transcendent noumena (Winkelman, 2018), it is nonetheless a neurophenomenological dynamic that should be explicated by neuropharmacology and ethnopharmacology (Winkelman, 2017).

In a real sense, ethnopharmacology falls in between two sciences: humans' perennial quest for empirical knowledge regarding the plants that can provide benefits to human health and well-being, embodied in countless cultural traditions; and a modernization of that impulse in the clinical and laboratory approaches to discovering and creating biochemicals and studying their effects on humans. The original thrust was expansive to include an understanding of the universe and its myriad of manifestations, many of them eminently conceptualized in spiritual terms. This is manifested in ethnopharmacological contributions to the emergence of an entheogenic paradigm, and as attested to in many of the articles in this second volume; it certainly stands as one of ethnopharmacology's significant societal contributions.

Michael James Winkelman

\section{REFERENCES}

Winkelman, M. (2017). Mechanisms of psychedelic visionary experiences: Hypotheses from evolutionary psychology. Frontiers in Neuroscience, 11, article 539. https://doi.org/10.3389/fnins. 2017.00539.

Winkelman, M. (2018). An ontology of psychedelic entity experiences in evolutionary psychology and neurophenomenology. Journal of Psychedelic Studies, 2(1), 5-23. https://doi.org/10. 1556/2054.2018.002. 